\title{
Research prioritization of men's health and urologic diseases
}

Tyler Okland ${ }^{1}$, Chante Karimkhani ${ }^{2}$, Hannah Pederson ${ }^{1}$, Lindsay N. Boyers ${ }^{3}$, Mark D. Sawyer ${ }^{4}$, Kyle 0. Rove ${ }^{5}$, McCabe C. Kenny ${ }^{5}$, Steven Steinberg ${ }^{4,5}$, Mohsen Naghavi ${ }^{6}$, Robert P. Dellavalle ${ }^{7,8,9}$

${ }^{1}$ University of Colorado School of Medicine, Aurora, Colorado, USA; ${ }^{2}$ College of Physicians and Surgeons, Columbia University, New York, NY, USA; ${ }^{3}$ School of Medicine, Georgetown University, Washington, District of Columbia, USA; ${ }^{4}$ Urology Service, Unites States Department of Veterans Affairs, Eastern Colorado Health Care System, Denver, Colorado, USA; ${ }^{5}$ Department of Urology, University of Colorado Anschutz Medical Campus, Aurora, Colorado, USA; ${ }^{6}$ Institute for Health Metrics and Evaluation, University of Washington, Seattle, Washington, USA; ${ }^{7}$ Department of Dermatology, University of Colorado Anschutz Medical Campus, Aurora, Colorado, USA; ${ }^{8}$ Dermatology Service, Unites States Department of Veterans, Eastern Colorado Health Care System, Denver, Colorado, USA; ${ }^{9}$ Department of Epidemiology, Colorado School of Public Health, University of Colorado Anschutz Medical Campus, Aurora, Colorado, USA

\section{ABSTRACT}

Objectives: We sought to determine whether disease representation in the Cochrane Database of Systematic Reviews (CDSR) reflects disease burden, measured by the Global Burden of Disease (GBD) Study as disability-adjusted life-years (DALYs).

Materials and Methods: Two investigators performed independent assessment of ten men's health and urologic diseases (MHUDs) in CDSR for systematic review and protocol representation, which were compared with percentage of total 2010 DALYs for the ten conditions. Data were analyzed for correlation using Spearman rank analysis. Results: Nine of ten MHUDs were represented by at least one CDSR review. There was a poor and statistically insignificant positive correlation between CDSR representation and disease burden ( $\mathrm{rho}=0.42, \mathrm{p}=0.23$ ). CDSR representation was aligned with disease burden for three conditions, greater than disease burden for one condition, and less than disease burden for six conditions.

Conclusions: These results yield high-quality estimates to inform future research prioritization for MHUDs. While prioritization processes are complex and multi-faceted, disease burden should be strongly considered. Awareness of research priority setting has the potential to minimize research disparities on a global scale.

\section{ARTICLE INFO}

\section{Keywords:}

Men's Health; Urologic Diseases; Neoplasms; Infertility, Male

Int Braz J Urol. 2017; 43: 289-303

Submitted for publication: April 04, 2016

Accepted after revision:

September 20, 2016

Published as Ahead of Print: January 06, 2017

\section{INTRODUCTION}

In order to achieve effective clinical research, scarce research funds must be distributed to appropriate diseases in order to maximize health benefits to the represented population. Systematic approaches to inform research prioritization include identifying and prioritizing research questions, recognizing existing research, and setting goals for primary research $(1,2)$. A derivative of this approach is to value major diseases, injuries, and risk factors based on their burden to society (3). Spearheaded by the Institute for Health Metrics and Evaluation (IHME), the Global Burden of Disease (GBD) 2010 Study estimates the burden of 291 diseases and injuries across 187 countries from 1990 to $2010(4,5)$. The metric of disability-adjusted life years (DALYs), in which 1 DALY is 
equivalent to 1 year of healthy life lost, allows for descriptive global epidemiology of a wide array of disease states. The following ten men's health and urologic diseases (MHUDs) were studied by GBD on the basis of prevalence, common case definitions, and data availability: tubulointerstitial nephritis, pyelonephritis, and urinary tract infections; kidney and other urinary organ cancers; urolithiasis; male infertility; benign prostatic hyperplasia; prostate cancer; testicular cancer; hydrocele due to lymphatic filariasis; dysuria/bladder pathology/ hydronephrosis due to schistosomiasis; and bladder cancer (Figure-1).

Systematic reviews are the cornerstone of evidence-based medicine, yet few efforts have been made to assess whether the prioritization of systematic reviews reflect global disease burden (6). The Cochrane Database of Systematic Reviews (CDSR) produces systematic reviews and protocols (published proposals for future systematic reviews) across all medical specialties as well as health systems, public health, and child development. Cochrane systematic reviews undergo exhaustive editorial processing, are more methodologically rigorous, and are updated more frequently than non-Cochrane reviews and paper-based journals $(7,8)$. Prior studies have evaluated the association between broad categories of disease burden with randomized trials and Cochrane systematic reviews (9-12). This study will assess whether the CDSR representation of ten MHUDs corresponds to GBD 2010 disability estimates.

\section{MATERIALS AND METHODS}

ICD-10 code definitions for the ten MHUDs have been previously published and were used to generate search terms, which were entered into the "title, abstract, keywords" CDSR search function $(5,13)$. Systematic reviews and protocols were

Figure 1 - Square pie chart representing percent of total DALY for ten men's health and urologic diseases; area of each square/rectangle represents percentage of total burden.

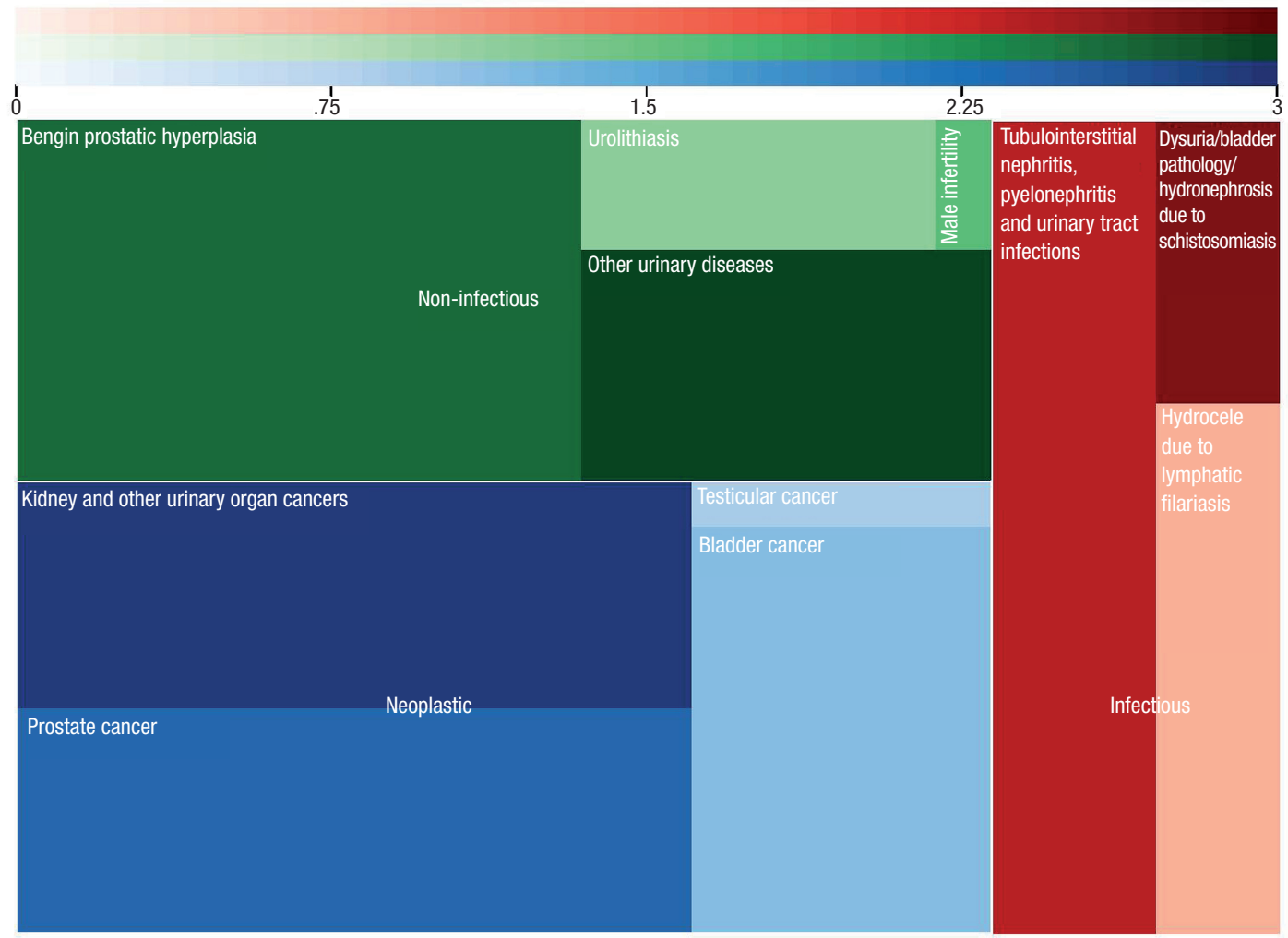

green $=$ non-infectious conditions, red $=$ infectious conditions, and $\mathbf{b l u e}=$ neoplastic conditions 
considered to determine MHUD representation in CDSR, according to abstract subject content. Online publication date, the number of studies included in each systematic review, and the particular Cochrane review group that published the review or protocol were collected.

Two authors (T.O and H.P.) collected data independently during February 2015. DALY metrics for each of the ten MHUDs, expressed as percentages of total DALY's of all 291 conditions measured in GBD 2010, were obtained from the GBD Compare interactive time plot, available at $<$ http://viz.healthmetricsandevaluation.org/gbd-compare/>. Spearman rank correlation analysis was performed to assess statistical dependence between CDSR representation and disease burden. Rho, a coefficient ranging from-1 (strong negative correlation) to +1 (strong positive correlation), is interpreted with a two-tailed p-value. A line-of-best-fit was also generated between CDSR representation and \% of total DALYs.

As this study did not involve human subjects, institutional review board approval was not necessary.

\section{RESULTS}

Nine of the ten MHUD conditions studied in GBD 2010 were represented by at least one systematic review. A total of 116 systematic reviews and protocols published by nine Cochrane review groups represented the ten MHUDs (Supporting Tables 1 and 2 for included and excluded titles, respectively). The majority of reviews and protocols covered tubulointerstitial nephritis, pyelonephritis, and urinary tract infections $(n=46)$. Hydrocele due to lymphatic filariasis had no representation in CDSR. Of the ten MHUDs, benign prostatic hyperplasia had the greatest global disease burden $(0.2 \%)$ while male infertility had the lowest (0.007\%) Table-1.

Reviews and protocols representing the ten MHUDs were published by the following Cochrane review groups: Prostatic Diseases and Urologic Cancers Group ( $\mathrm{n}=43$ ); Renal Group (36); Incontinence Group (14); Menstrual Disorders and Subfertility Group (8); Pregnancy and Childbirth Group (7); Infectious Diseases Group (3); Pain,
Palliative and Supportive Care Group (2); Gynecological Cancer Group (2); and Neonatal Group (1).

Spearman rank correlation testing between CDSR representation and DALY metrics revealed poor positive correlation that was statistically insignificant ( $\mathrm{rho}=0.41, \mathrm{p}=0.21$ ). The majority of the MHUDs (6) were under-represented in CDSR as compared to GBD DALY (Figure-2). Most of the systematic reviews and protocols (58.6\%) were published from 2011 to 2015 while $37.9 \%$ were published from 2000 to 2010; only 4 reviews were published prior to 2000. Maintaining systematic reviews up-to-date is critical to deliver consensus statements on current world literature that ultimately impact clinical decisions and patient outcomes.

Representation of tubulointerstitial nephritis, pyelonephritis, and urinary tract infections exceeded GBD disease burden. This disease category also had the greatest number of cumulative studies informing its systematic reviews (529). The one systematic review representing testicular cancer, entitled "Screening for testicular cancer," found no randomized controlled trials in the literature. Systematic reviews that find no suitable trials to address their objectives uncover areas for much-needed, high-quality research.

The World Health Organization (WHO) classifies two of the MHUDs as neglected tropical diseases: dysuria/bladder pathology/hydronephrosis due to schistosomiasis and hydrocele due to lymphatic filariasis (14). It is important to note that just as the DALY metrics reported for these two diseases include only burden due to the MHUD morbidity (dysuria, bladder pathology, hydronephrosis, hydrocele), systematic reviews were only considered representative if they included assessment of the MHUD pathology.

\section{DISCUSSION}

We acknowledge several limitations of our study. The scope of CDSR systematic reviews is subject to variability. For instance, authors may prepare one large review of multiple interventions (lumping) or several reviews of individual interventions (splitting). Therefore, treating a systematic review or protocol as one measurement unit may not be entirely accurate for every topic. 


\section{Supporting Table 1}

\begin{tabular}{|c|c|c|c|c|}
\hline Injury or Trauma & Review $(\mathrm{R})$ or Protocol $(\mathrm{P})$ Title & Cochrane Group & Number of Studies & $\begin{array}{l}\text { Year of Online } \\
\text { Publication }\end{array}$ \\
\hline \multirow{19}{*}{$\begin{array}{l}\text { Tubulo-interstitial } \\
\text { nephritis, } \\
\text { pyelonephritis, and } \\
\text { urinary tract infections }\end{array}$} & Antibiotics for acute pyelonephritis in children (R) & Renal Group & 27 & 2007 \\
\hline & Antibiotics for asymptomatic bacteriuria in pregnancy $(R)$ & $\begin{array}{l}\text { Pregnancy and Childbirth } \\
\text { Group }\end{array}$ & 14 & 2007 \\
\hline & $\begin{array}{l}\text { Treatments for symptomatic urinary tract infections } \\
\text { during pregnancy }(\mathrm{R})\end{array}$ & $\begin{array}{l}\text { Pregnancy and Childbirth } \\
\text { Group }\end{array}$ & 10 & 2011 \\
\hline & $\begin{array}{l}\text { Duration of treatment for asymptomatic bacteriuria during } \\
\text { pregnancy }(\mathrm{R})\end{array}$ & $\begin{array}{l}\text { Pregnancy and Childbirth } \\
\text { Group }\end{array}$ & 13 & 2011 \\
\hline & $\begin{array}{l}\text { Routine blood cultures in the management of } \\
\text { pyelonephritis in pregnancy for improving outcomes (R) }\end{array}$ & Renal Group & 0 & 2015 \\
\hline & $\begin{array}{c}\text { Procalcitonin , C-reactive protein , and erythrocyte } \\
\text { sedimentation rate for the diagnosis of acute } \\
\text { pyelonephritis in children (R) }\end{array}$ & Renal Group & 17 & 2015 \\
\hline & $\begin{array}{l}\text { Duration of antibacterial treatment for uncomplicated } \\
\text { urinary tract infection in women }(\mathrm{R})\end{array}$ & Renal Group & 32 & 2005 \\
\hline & $\begin{array}{l}\text { Interventions for preventing recurrent urinary tract } \\
\text { infection during pregnancy }(R)\end{array}$ & $\begin{array}{l}\text { Pregnancy and Childbirth } \\
\text { Group }\end{array}$ & 1 & 2012 \\
\hline & $\begin{array}{l}\text { Long-term antibiotics for preventing recurrent urinary } \\
\text { tract infection in children }(R)\end{array}$ & Renal Group & 12 & 2011 \\
\hline & $\begin{array}{l}\text { Treatments for symptomatic urinary tract infections } \\
\text { during pregnancy }(\mathrm{R})\end{array}$ & $\begin{array}{l}\text { Pregnancy and Childbirth } \\
\text { Group }\end{array}$ & 10 & 2011 \\
\hline & $\begin{array}{l}\text { Prophylactic antibiotics to reduce the risk of urinary tract } \\
\text { infections after urodynamic studies }(R)\end{array}$ & Incontinence Group & 9 & 2012 \\
\hline & $\begin{array}{l}\text { Types of indwelling urethral catheters for short-term } \\
\text { catheterization in hospitalized adults (R) }\end{array}$ & Incontinence Group & 26 & 2014 \\
\hline & $\begin{array}{l}\text { Antibiotics for treating lower urinary tract infection in } \\
\text { children }(R)\end{array}$ & Renal Group & 16 & 2012 \\
\hline & $\begin{array}{l}\text { Methenamine hippurate for preventing urinary tract } \\
\text { infections }(\mathrm{R})\end{array}$ & Renal Group & 13 & 2012 \\
\hline & $\begin{array}{l}\text { Estrogens for preventing recurrent urinary tract infection } \\
\text { in postmenopausal women }(\mathrm{R})\end{array}$ & Renal Group & 9 & 2008 \\
\hline & $\begin{array}{l}\text { Short versus standard duration oral antibiotic therapy for } \\
\text { acute urinary tract infection in children }(\mathrm{R})\end{array}$ & Renal Group & 10 & 2003 \\
\hline & $\begin{array}{l}\text { Urinary catheter policies for long-term bladder } \\
\text { drainage }(\mathrm{R})\end{array}$ & Incontinence Group & 8 & 2012 \\
\hline & $\begin{array}{l}\text { Antimicrobial agents for treating uncomplicated urinary } \\
\text { tract infection in women }(\mathrm{R})\end{array}$ & Renal Group & 21 & 2010 \\
\hline & $\begin{array}{l}\text { Modes of administration of antibiotics for symptomatic } \\
\text { severe urinary tract infections }(\mathrm{R})\end{array}$ & Renal Group & 15 & 2007 \\
\hline
\end{tabular}




\footnotetext{
Antibiotic duration for treating uncomplicated, symptomatic lower urinary tract infections in elderly women $(\mathrm{R})$

Antibiotic prophylaxis for short-term catheter bladder drainage in adults $(\mathrm{R})$

Cranberries for treating urinary tract infections (R)

Antibiotics for preventing recurrent urinary tract infection in non-pregnant women $(R)$

Cranberries for preventing urinary tract infections $(R)$

Routine neonatal circumcision for the prevention of urinary tract infections in infancy $(\mathrm{R})$

Urinary catheter policies for short-term bladder drainage in adults $(R)$

Intermittent catheterization for long-term bladder management (R)
}

Antibiotic prophylaxis for transrectal prostate biopsy (R)

Short term urinary catheter policies following urogenital surgery in adults $(R)$

Washout policies in long-term indwelling urinary catheterization in adults $(R)$

Routine intraoperative ureteric stenting for kidney transplant recipients $(\mathrm{R})$

Interventions for primary vesicoureteric reflux (R)

Types of indwelling urinary catheters for long-term bladder drainage in adults $(\mathrm{R})$

Laser prostatectomy for benign prostatic obstruction $(\mathrm{R})$

Quinolones for uncomplicated acute cystitis in women $(\mathrm{R})$

Drugs for treatment of urinary retention after surgery in adults $(\mathrm{R})$

Indwelling bladder catheterization as part of intraoperative and postoperative care for caesarean section $(R)$

Dietary interventions for preventing complications in idiopathic hypercalciuria $(R)$

Interventions for covert bacteriuria in children (R)

Pharmacological interventions for preventing complications in idiopathic hypercalciuria $(R)$

Different antibiotic regimens for treating asymptomatic bacteriuria in pregnancy $(R)$

Urinary alkalization for uncomplicated urinary tract infection $(P)$
Renal Group

Incontinence Group

6

2013

Renal Group

0

1998

Renal Group

19

2004

Renal Group

24

2012

Neonatal Group

0

Incontinence Group

17

2005

Incontinence Group

31

Prostatic Diseases and

19

2011

Urologic Cancers Group

Incontinence Group

39

Incontinence Group

5

2010

Renal Group

7

Renal Group

20

Incontinence Group

3

Prostatic Diseases and

20

Urologic Cancers Group

Renal Group

11

Incontinence Group

7

2010

Pregnancy and Childbirth

5

Group

Renal Group

5

2014

Renal Group

Renal Group

3

5

2009

Pregnancy and Childbirth

5

Group

Renal Group

N/A

2013 
Kidney and other urinary organ cancers

Urolithiasis

Male infertility
Dimercaptosuccinic acid scan versus ultrasound in

screening for vesicoureteral reflux among children with urinary tract infections $(P)$

Chinese herbal medicine for treating recurrent urinary tract infections in women $(P)$

Probiotics for preventing urinary tract infection in people with neuropathic bladder $(\mathrm{P})$

Probiotics for preventing urinary tract infections in adults and children $(P)$

Targeted therapy for advanced renal cell carcinoma (R)

Immunotherapy for advanced renal cell cancer (R)

Surgical management of localized renal cell carcinoma $(\mathrm{R})$

Surgical management for upper urinary tract transitional cell carcinoma $(\mathrm{R})$

Extracorporeal shock wave lithotripsy (ESWL) versus percutaneous nephrolithotomy (PCNL) or retrograde intrarenal surgery (RIRS) for kidney stones (R)

Dietary interventions for preventing complications in idiopathic hypercalciuria $(\mathrm{R})$

Extracorporeal shock wave lithotripsy (ESWL) versus ureteroscopic management for ureteric calculi $(\mathrm{R})$

Pharmacological interventions for preventing complications in idiopathic hypercalciuria (R)

Fluids and diuretics for acute ureteric colic (R)

Water for preventing urinary stones $(R)$

Alpha-blockers as medical expulsive therapy for ureteral stones $(\mathrm{R})$

Percussion, diuresis, and inversion therapy for the passage of lower pole kidney stones following shock wave lithotripsy $(R)$

Analgesia for patients undergoing shockwave lithotripsy for urinary stones $(P)$

Interventions for treating urinary stones in children $(\mathrm{P})$

Intra-uterine insemination for male subfertility (R)

Antioxidants for male subfertility (R)

Surgery or embolization for varicoceles in subfertile men (R)

Regular (ICSI ) versus ultra-high magnification (IMSI) sperm selection for assisted reproduction ( $R$ )

$$
\text { Renal Group }
$$

Urologic Cancers Group

Prostatic Diseases and

Urologic Cancers Group

Prostatic Diseases and

Urologic Cancers Group

Prostatic Diseases and

Urologic Cancers Group

Renal Group

Renal Group

Renal Group

Renal Group

Renal Group

Renal Group

Renal Group

Renal Group

Renal Group

N/A

2013

Menstrual Disorders and

Subfertility Group

Menstrual Disorders and Subfertility Group

Menstrual Disorders and 
Benign prostatic hyperplasia

Prostate cancer

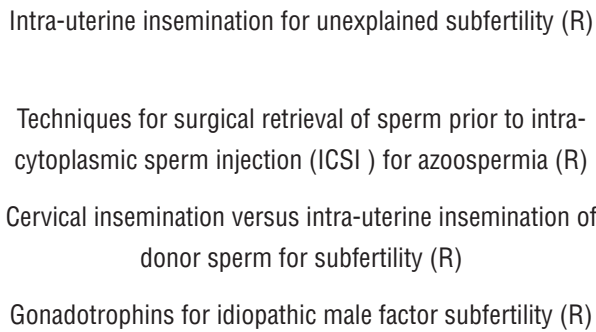

Pygeum africanum for benign prostatic hyperplasia (R)

Finasteride for benign prostatic hyperplasia (R)

Beta-sitosterols for benign prostatic hyperplasia (R)

Serenoa repens for benign prostatic hyperplasia $(R)$

Naftopidil for the treatment of lower urinary tract symptoms compatible with benign prostatic hyperplasia $(\mathrm{R})$

Microwave thermotherapy for benign prostatic hyperplasia $(\mathrm{R})$

Phosphodiesterase inhibitors for lower urinary tract symptoms consistent with benign prostatic hyperplasia (P)

Laser prostatectomy for benign prostatic obstruction (R)

Bipolar versus monopolar transurethral resection of the prostate for lower urinary tract symptoms secondary to benign prostatic obstruction $(\mathrm{P})$

5-alpha-reductase inhibitors for prostate cancer prevention $(\mathrm{R})$

Screening for prostate cancer (R)

Lycopene for the prevention of prostate cancer (R)

Psychosocial interventions for men with prostate cancer $(\mathrm{R})$

Radical prostatectomy versus watchful waiting for prostate cancer (R)

Bisphosphonates for advanced prostate cancer (R)

Cryotherapy for localized prostate cancer (R)
Menstrual Disorders and

$$
\text { Subfertility Group }
$$

Menstrual Disorders and

Subfertility Group

Menstrual Disorders and Subfertility Group

Menstrual Disorders and Subfertility Group

Prostatic Diseases and Urologic Cancers Group

Prostatic Diseases and Urologic Cancers Group

Prostatic Diseases and Urologic Cancers Group

Prostatic Diseases and Urologic Cancers Group

Prostatic Diseases and

Urologic Cancers Group

Prostatic Diseases and

Urologic Cancers Group

Prostatic Diseases and

Urologic Cancers Group

Prostatic Diseases and

Urologic Cancers Group

Prostatic Diseases and

Urologic Cancers Group

Prostatic Diseases and

9

Urologic Cancers Group

Prostatic Diseases and

Urologic Cancers Group

Prostatic Diseases and

Urologic Cancers Group

Prostatic Diseases and

Urologic Cancers Group

Prostatic Diseases and

Urologic Cancers Group

Prostatic Diseases and

Urologic Cancers Group

Prostatic Diseases and

Urologic Cancers Group
2012

2008

2008

1998 
Neo- adjuvant and adjuvant hormone therapy for localized and locally advanced prostate cancer (R)

Early versus deferred androgen suppression in the treatment of advanced prostatic cancer $(\mathrm{R})$

Chemotherapy for hormone-refractory prostate cancer $(\mathrm{R})$

Maximal androgen blockade for advanced prostate cancer $(\mathrm{R})$

Adjuvant radiotherapy following radical prostatectomy for prostate cancer $(\mathrm{R})$

Intermittent versus continuous androgen suppression for prostatic cancer $(\mathrm{R})$

Low-dose rate brachytherapy for men with localized prostate cancer $(\mathrm{R})$

Interventions for sexual dysfunction following treatments for cancer $(R)$

Green tea (Camellia sinensis) for the prevention of cancer (R)

Exercise for the management of cancer-related fatigue in adults ( $R$ )

Laparoscopic versus open prostatectomy for the treatment of localized prostate cancer $(\mathrm{P})$

Non-steroidal antiandrogen monotherapy compared with luteinizing hormone -releasing hormone agonists or surgical castration monotherapy for advanced prostate cancer $(\mathrm{R})$

Conservative management for postprostatectomy urinary incontinence $(\mathrm{R})$

Surgery for stress urinary incontinence due to presumed sphincter deficiency after prostate surgery ( $R$ )

Antibiotic prophylaxis for transrectal prostate biopsy $(R)$

Testicular cancer

Screening for testicular cancer (R)

Bladder cancer
Selenium for preventing cancer $(R)$
Prostatic Diseases and

Urologic Cancers Group

Prostatic Diseases and

Urologic Cancers Group

Prostatic Diseases and

Urologic Cancers Group

Prostatic Diseases and

Urologic Cancers Group

Prostatic Diseases and

Urologic Cancers Group

Prostatic Diseases and

Urologic Cancers Group

Prostatic Diseases and

Urologic Cancers Group

Pain, Palliative and Supportive

Care Group

Gynaecological Cancer Group

Gynaecological Cancer Group

Pain, Palliative and Supportive

Care Group

Prostatic Diseases and

Urologic Cancers Group

Prostatic Diseases and

Urologic Cancers Group

Incontinence Group

50

Incontinence Group

Prostatic Diseases and

Urologic Cancers Group

Prostatic Diseases and

Urologic Cancers Group

Prostatic Diseases and

Urologic Cancers Group

Prostatic Diseases and

Urologic Cancers Group

Prostatic Diseases and

Urologic Cancers Group

Prostatic Diseases and

Urologic Cancers Group
Gemcitabine for unresectable , locally advanced or metastatic bladder cancer $(\mathrm{R})$

Intravesical Bacillus Calmette-Guérin in Ta and T1 bladder cancer (R)
1 


$$
\begin{aligned}
& \text { Neo-adjuvant chemotherapy for invasive bladder } \\
& \text { cancer (R) }
\end{aligned}
$$

Intravesical Bacillus Calmette-Guérin versus mitomycin C

for Ta and T1 bladder cancer (R)

Surgery versus radiotherapy for muscle invasive bladder cancer $(R)$

Adjuvant chemotherapy for invasive bladder cancer (individual patient data) (R)

Green tea (Camellia sinensis) for the prevention of cancer (R)

Perioperative nutrition for the treatment of bladder cancer by radical cystectomy $(\mathrm{P})$

Urinary diversion and bladder reconstruction / replacement using intestinal segments for intractable incontinence or following cystectomy (R)

Hydrocele due to

lymphatic filariasis

Dysuria/bladder pathology/ hydronephrosis due to schistosomiasis
Prostatic Diseases and

Urologic Cancers Group

Prostatic Diseases and

Urologic Cancers Group

Prostatic Diseases and

Urologic Cancers Group

Prostatic Diseases and

Urologic Cancers Group

Gyanecological Cancer Group

Prostatic Diseases and

Urologic Cancers Group

Incontinence Group

Therapeutic and prophylactic drug interventions for

Schistosomiasis japonicum $(P)$

Rapid screening and diagnostic tests for human schistosomiasis in endemic areas $(P)$

Urinary diversion and bladder reconstruction/replacement using intestinal segments for intractable incontinence or following cystectomy (R)
Infectious Diseases Group

$N / A$

2012

N/A

Incontinence Group

5
Infectious Diseases Group 
Supporting Table 2:

\begin{tabular}{|c|c|}
\hline Condition & Review $(\mathrm{R})$ or Protocol $(\mathrm{P})$ \\
\hline \multirow{31}{*}{$\begin{array}{l}\text { Tubulo-interstitial nephritis, } \\
\text { pyelonephritis, and urinary tract } \\
\text { infections }\end{array}$} & Interventions to improve professional adherence to guidelines for prevention of device-related infections (R) \\
\hline & Mechanical dilatation of the cervix at non-labour caesarean section for reducing postoperative morbidity $(\mathrm{R})$ \\
\hline & Antibiotic prophylaxis versus no prophylaxis for preventing infection after cesarean section (R) \\
\hline & Traditional suburethral sling operations for urinary incontinence in women $(R)$ \\
\hline & Antibiotic prophylaxis for surgery for proximal femoral and other closed long bone fractures $(R)$ \\
\hline & Mupirocin ointment for preventing Staphylococcus aureus infections in nasal carriers (R) \\
\hline & Rituximab for relapsing-remitting multiple sclerosis $(\mathrm{R})$ \\
\hline & Beta lactam antibiotic monotherapy versus beta lactam -aminoglycoside antibiotic combination therapy for sepsis $(R)$ \\
\hline & Habit retraining for the management of urinary incontinence in adults $(R)$ \\
\hline & Preoperative skin antiseptics for preventing surgical wound infections after clean surgery (R) \\
\hline & Antibiotic prophylaxis for cirrhotic patients with upper gastrointestinal bleeding $(R)$ \\
\hline & Antimicrobial therapy for chronic bacterial prostatitis $(R)$ \\
\hline & Cyanoacrylate microbial sealants for skin preparation prior to surgery $(R)$ \\
\hline & Perioperative increase in global blood flow to explicit defined goals and outcomes following surgery (R) \\
\hline & Interventions to improve antibiotic prescribing practices in ambulatory care $(R)$ \\
\hline & Teriflunomide for multiple sclerosis $(R)$ \\
\hline & Laquinimod for multiple sclerosis (R) \\
\hline & Mitoxantrone for multiple sclerosis $(R)$ \\
\hline & Efficacy and safety of cesarean delivery for prevention of mother-to-child transmission of HIV-1 (R) \\
\hline & Surgical approach to hysterectomy for benign gynecological disease $(R)$ \\
\hline & Interventions for preventing mastitis after childbirth $(\mathrm{R})$ \\
\hline & Laparoscopy versus laparotomy for benign ovarian tumor (R) \\
\hline & Valproate preparations for agitation in dementia $(\mathrm{R})$ \\
\hline & Regional versus general anesthesia for caesarean section $(R)$ \\
\hline & Interventions for promoting the initiation of breastfeeding $(R)$ \\
\hline & $\begin{array}{l}\text { Protocolized versus non- protocolized weaning for reducing the duration of mechanical ventilation in critically ill adult } \\
\text { patients }(R)\end{array}$ \\
\hline & In-hospital care pathways for stroke $(\mathrm{R})$ \\
\hline & Schedules for home visits in the early postpartum period $(R)$ \\
\hline & Short term benefits for laparoscopic colorectal resection $(R)$ \\
\hline & Diaphragm versus diaphragm with spermicides for contraception (R) \\
\hline & Cervical cap versus diaphragm for contraception (R) \\
\hline \multirow{7}{*}{$\begin{array}{l}\text { Kidney and other urinary organ } \\
\text { cancers }\end{array}$} & Early and late renal adverse effects after potentially nephrotoxic treatment for childhood cancer (R) \\
\hline & \\
\hline & Urate oxidase for the prevention and treatment of tumor lysis syndrome in children with cancer $(R)$ \\
\hline & Bisphosphonates and other bone agents for breast cancer $(R)$ \\
\hline & Interventions for preventing non-melanoma skin cancers in high-risk groups ( $R$ ) \\
\hline & Perioperative blood transfusions and recurrence of colorectal cancer (R) \\
\hline & Medical interventions for the prevention of platinum-induced hearing loss in children with cancer (R) \\
\hline
\end{tabular}


Cisplatin versus carboplatin in combination with third-generation drugs for advanced non-small cell lung cancer (R)

Immunosuppressive T-cell antibody induction for heart transplant recipients $(\mathrm{R})$

Concomitant hydroxyurea plus radiotherapy versus radiotherapy for carcinoma of the uterine cervix $(R)$

Amphotericin $B$ versus fluconazole for controlling fungal infections in neutropenic cancer patients $(R)$

HMG CoA reductase inhibitors (statins) for dialysis patients $(R)$

Urinary diversion and bladder reconstruction /replacement using intestinal segments for intractable incontinence or following cystectomy $(\mathrm{R})$

Pharmacological interventions for pruritus in adult palliative care patients $(R)$

Homocysteine-lowering interventions for preventing cardiovascular events (R)

HMG CoA reductase inhibitors (statins) for kidney transplant recipients $(R)$

Vitamin D supplementation for prevention of mortality in adults $(R)$

Vitamin $D$ and vitamin $D$ analogues for preventing fractures in post-menopausal women and older men (R)

Antibody induction therapy for lung transplant recipients $(\mathrm{R})$

First-line tandem high-dose chemotherapy and autologous stem cell transplantation versus single high-dose chemotherapy and autologous stem cell transplantation in multiple myeloma, a systematic review of controlled studies $(R)$

Antibiotic prophylaxis for preventing post solid organ transplant tuberculosis $(\mathrm{R})$

Tacrolimus versus cyclosporin as primary immunosuppression for lung transplant recipients (R)

Bisphosphonates in multiple myeloma: a network meta-analysis $(\mathrm{R})$

Darbepoetin for the anemia of chronic kidney disease $(\mathrm{R})$

Selenium for preventing cancer (R)

Hyperbaric oxygenation for tumor sensitization to radiotherapy $(\mathrm{R})$

Adjuvant radiotherapy following radical prostatectomy for prostate cancer (R)

Exenterative surgery for recurrent gynecological malignancies $(R)$

Laparoscopically assisted radical vaginal hysterectomy versus radical abdominal hysterectomy for the treatment of early cervical cancer $(\mathrm{R})$

Laparoscopy versus laparotomy for the management of early stage endometrial cancer (R)

Laparoscopic versus open total mesorectal excision for rectal cancer (R)

Adjuvant radiotherapy for stage I endometrial cancer $(\mathrm{R})$

Cryotherapy for localized prostate cancer (R)

Spinal cord stimulation for cancer -related pain in adults $(R)$

Chemoradiation for advanced primary vulval cancer $(\mathrm{R})$

High dose rate versus low dose rate intracavity brachytherapy for locally advanced uterine cervix cancer (R)

Surgical management for upper urinary tract transitional cell carcinoma $(R)$

Cholecystectomy for patients with silent gallstones $(R)$

Drugs for treating urinary schistosomiasis $(R)$

Non-surgical interventions for late radiation cystitis in patients who have received radical radiotherapy to the pelvis $(R)$

Cranberries for preventing urinary tract infections $(R)$

Radioiodine therapy for differentiated thyroid carcinoma with thyroglobulin positive and radioactive iodine negative metastases $(\mathrm{R})$

Conservative management for postprostatectomy urinary incontinence $(\mathrm{R})$

Surgery for stress urinary incontinence due to presumed sphincter deficiency after prostate surgery $(R)$

The role of alpha blockers prior to removal of urethral catheter for acute urinary retention in men (R) 
Male infertility

Benign prostatic hyperplasia

Prostate cancer

Testicular cancer

Bladder cancer

Hydrocele due to lymphatic filariasis

Dysuria/bladder pathology/ hydronephrosis due to schistosomiasis
Fluids and diuretics for acute ureteric colic (R)

Vitamin $D$ supplementation for prevention of mortality in adults $(R)$

Chinese medicinal herbs for cholelithiasis $(R)$

Thyroid hormones for acute kidney injury (R)

Vitamin $D$ and vitamin $D$ analogues for preventing fractures in post-menopausal women and older men $(R)$ Intra-cytoplasmic sperm injection versus conventional techniques for oocyte insemination during in vitro fertilisation in couples with non-male subfertility $(R)$

Oral 5-aminosalicylic acid for induction of remission in ulcerative colitis (R)

Oral 5 -aminosalicylic acid for maintenance of remission in ulcerative colitis (R) Intrauterine insemination versus fallopian tube sperm perfusion for non-tubal infertility (R)

Vasectomy occlusion techniques for male sterilization $(R)$

Steroid hormones for contraception in men $(\mathrm{R})$

Interventions for chronic abacterial prostatitis $(\mathrm{R})$

Interventions for improving the adoption of shared decision making by healthcare professionals $(R)$

Chemotherapy for malignant germ cell ovarian cancer in adult patients with early stage, advanced and recurrent disease

(R)

Cholecystectomy for patients with silent gallstones $(R)$

Hyperbaric oxygenation for tumor sensitization to radiotherapy $(R)$

Drugs for treating urinary schistosomiasis $(\mathrm{R})$

High dose rate versus low dose rate intracavity brachytherapy for locally advanced uterine cervix cancer (R)

Adjuvant radiotherapy for stage I endometrial cancer $(\mathrm{R})$

Laparoscopy versus laparotomy for the management of early stage endometrial cancer (R)

Selenium for preventing cancer $(R)$

Radioiodine therapy for differentiated thyroid carcinoma with thyroglobulin positive and radioactive iodine negative metastases $(\mathrm{R})$

Chemoradiation for advanced primary vulval cancer $(\mathrm{R})$

Laparoscopic versus open total mesorectal excision for rectal cancer $(\mathrm{R})$

Spinal cord stimulation for cancer-related pain in adults $(R)$

Albendazole for lymphatic filariasis $(R)$

Diethylcarbamazine (DEC)-medicated salt for community-based control of lymphatic filariasis (R)

Metrifonate for Alzheimer's disease (R)

Drugs for treating Schistosoma mansoni infection (R) 
Table 1 - Men's health and urologic diseases studied by GBD 2010 with corresponding ICD-10 codes, search terms, number of systematic reviews (R) and protocols (P) in CDSR, percent of total DALYs (arranged in order of decreasing $\%$ of total DALY), and number of studies included in Cochrane reviews.

\begin{tabular}{|c|c|c|c|c|c|}
\hline Condition & ICD-10 code & Search terms & $\begin{array}{c}\text { Number of cochrane } \\
\text { reviews }(R) \& \\
\text { protocols }(P)\end{array}$ & $\begin{array}{l}\% \text { total } 210 \text { dalys (out } \\
\text { of } 291 \text { conditions) }\end{array}$ & $\begin{array}{c}\text { Number of studies in } \\
\text { cochrane review }\end{array}$ \\
\hline Benign prostatic hyperplasia & N40 & $\begin{array}{l}\text { "benign prostatic hyperplasia" } \\
\text { "median bar" } \\
\text { "prostatic hyperplasia" } \\
\text { "adenofibromatous } \\
\text { hypertrophy of prostrate" } \\
\text { "hypertrophy of prostate } \\
\text { "prostatic obstruction" }\end{array}$ & $9(7 \mathrm{R}, 2 \mathrm{P})$ & $0.2 \%$ & 35 \\
\hline Prostate cancer & $\begin{array}{l}\text { C61, D07.5 } \\
\quad \text { D40.0 }\end{array}$ & $\begin{array}{l}\text { "prostate cancer" } \\
\text { "prostatic carcinoma in situ" } \\
\text { "prostate neoplasm" }\end{array}$ & $23(22 \mathrm{R}, 1 \mathrm{P})$ & $0.15 \%$ & 411 \\
\hline $\begin{array}{l}\text { Kidney and other urinary organ } \\
\text { cancers }\end{array}$ & $\begin{array}{c}\text { C64-C66, } \\
\text { D41.0-D41.2 }\end{array}$ & $\begin{array}{l}\text { "kidney cancer" } \\
\text { "neoplasm of the ureter" } \\
\text { "neoplasm of the kidney" } \\
\text { "neoplasm of the renal pelvis" }\end{array}$ & $4(4 \mathrm{R})$ & $0.15 \%$ & 63 \\
\hline $\begin{array}{l}\text { Tubulointerstitial nephritis, } \\
\text { pyelonephritis, and urinary tract } \\
\text { infections }\end{array}$ & $\begin{array}{l}\text { N10-N12, } \\
\text { N15.1-N15.9, } \\
\text { N30, N34, } \\
\text { N39.0 }\end{array}$ & $\begin{array}{l}\text { "tubulointerstitial nephritis" } \\
\text { "pyelonephritis" } \\
\text { "urinary tract infections" } \\
\text { "infectious interstitial } \\
\text { nephritis" } \\
\text { "pyelitis" } \\
\text { "balkan nephropathy" } \\
\text { "renal and perinephric } \\
\text { abscess" } \\
\text { "cystitis" } \\
\text { "trigonitis" } \\
\text { "urethral abscess" } \\
\text { "urethritis" }\end{array}$ & $46(41 \mathrm{R}, 5 \mathrm{P})$ & $0.13 \%$ & 529 \\
\hline Bladder cancer & $\begin{array}{l}\text { C67, D09.0* } \\
\text { D41.4 }\end{array}$ & $\begin{array}{l}\text { "bladder cancer" } \\
\text { "bladder carcinoma" } \\
\text { "bladder neoplasm" }\end{array}$ & $11(10 \mathrm{R}, 1 \mathrm{P})$ & $0.12 \%$ & 106 \\
\hline $\begin{array}{l}\text { Hydrocele due to lymphatic } \\
\text { filariasis }\end{array}$ & $\begin{array}{l}\text { B74 (except } \\
\text { B74.3, B74.4, } \\
\text { B74.8, B74.9) }\end{array}$ & $\begin{array}{l}\text { "Iymphatic filariasis" } \\
\text { [hydrocele] }\end{array}$ & 0 & $0.064 \%$ & 0 \\
\hline Urolithiasis & N20-N23 & $\begin{array}{l}\text { "urolithiasis" } \\
\text { "urinary stones" } \\
\text { "nephrolithiasis" } \\
\text { "kidney stones" } \\
\text { "ureterolithiasis" } \\
\text { "cystolithiasis" } \\
\text { "bladder stones" }\end{array}$ & $10(8 \mathrm{R}, 2 \mathrm{P})$ & $0.045 \%$ & 59 \\
\hline $\begin{array}{l}\text { Dysuria/bladder pathology/ } \\
\text { hydronephrosis due to } \\
\text { schistosomiasis }\end{array}$ & B65 & $\begin{array}{l}\text { "schistosomiasis" [dysuria, } \\
\text { bladder, hydronephrosis] }\end{array}$ & $4(2 \mathrm{R}, 2 \mathrm{P})$ & $0.034 \%$ & 35 \\
\hline Testicular cancer & C62, D40.1 & $\begin{array}{c}\text { "testicular cancer" } \\
\text { "malignant neoplasm of testis" }\end{array}$ & $1 \mathrm{R}$ & $0.013 \%$ & 0 \\
\hline Male infertility & N46 & $\begin{array}{l}\text { "azoospermia" } \\
\text { "oligospermia" }\end{array}$ & $8 \mathrm{R}$ & 0.007 & 95 \\
\hline
\end{tabular}


Figure 2 - Comparison of men's health and urologic disease representation in the Cochrane Database of Systematic Reviews with percent of 2010 DALYs from 291 conditions studied by GBD 2010.

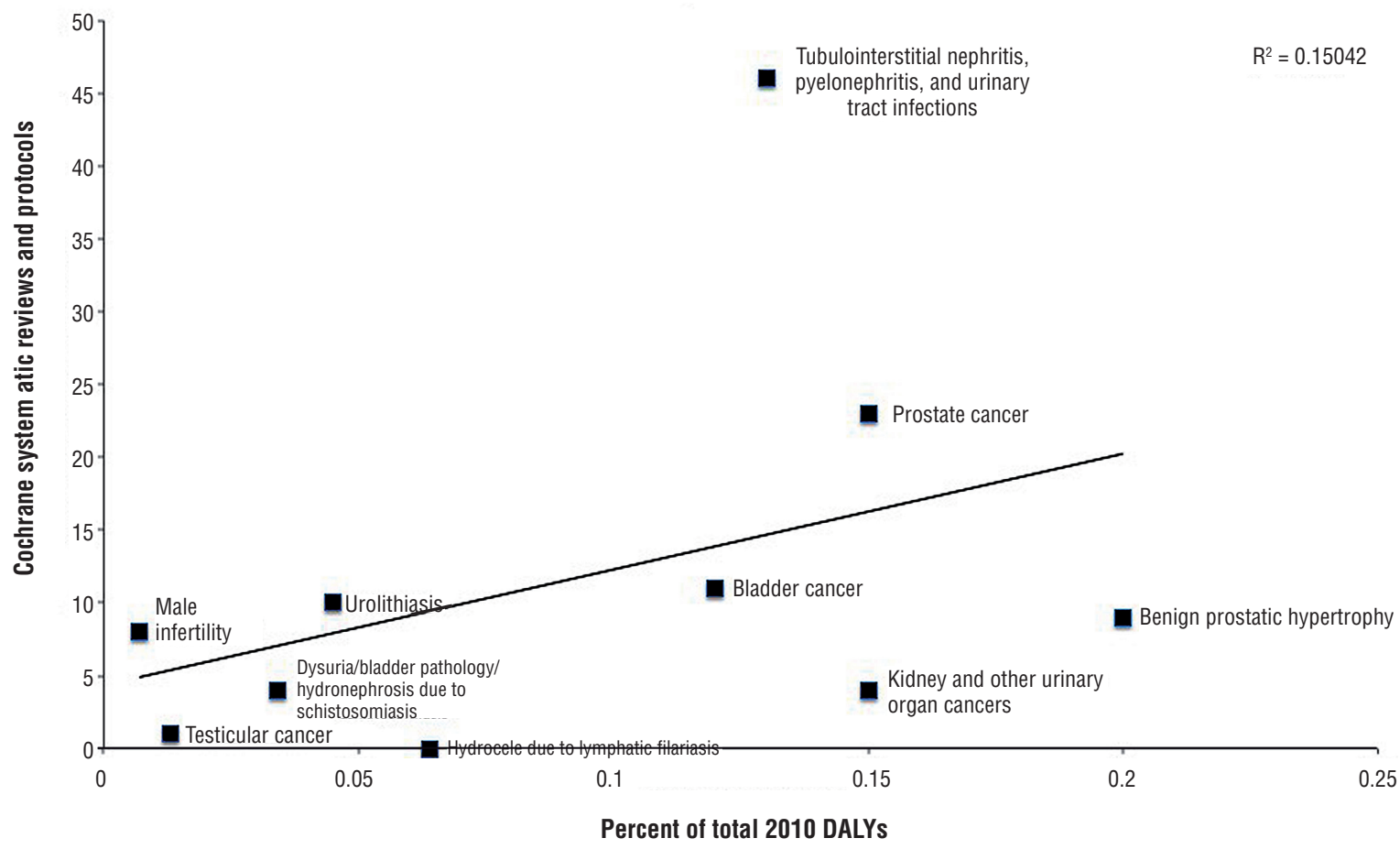

While beyond the scope of this limited study, further exploration is warranted into potential underrepresentation of certain conditions.

There remains a lack of transparency in publications and databases on the quality of data and criteria involved in prioritization decisions (15). Other important factors in priority setting include availability of research funds, knowledge gap, and impact on disadvantaged populations. Research prioritization is also inherently political and dependent on financial backing, which further demonstrates the importance of a transparent process. Attention and awareness of priority setting has the potential to minimize research disparities and, ultimately, impact populations at a global scale.

\section{ACKNOWLEDGEMENTS:}

Tyler Okland and Chante Karimkhani are contributed similarly as first authors.

Luc Coffeng MD, Department of $\mathrm{Pu}$ blic Health at Erasmus MC University Medical
Center, Rotterdam, Nederlands.

Megan Coggeshall BA, Institute for Health Metrics and Evaluation, University of Washington, Seattle, WA.

\section{FINANCIAL SUPPORT}

There was no direct funding to the current study. The Global Burden of Disease study received funding from the Bill and Melinda Gates Foundation (PI: Christopher J.L. Murray). Lindsay Boyers, Mark Sawyer, and Robert Dellavalle are employees of the U.S. Department of Veterans Affairs. The U.S. Department of Veterans Affairs had no role in the design and execution of the study. Robert Dellavalle is supported by grants from the CDC and National Institutes of Health. Tyler Okland, Chante Karimkhani, Hannah Pederson, Lindsay Boyers, Mohsen Naghavi, and Mark Sawyer report no relevant disclosures. Any opinions expressed herein do not necessarily reflect the opinions of the CDC or the Department of Veterans Affairs. 


\section{CONFLICT OF INTEREST}

\author{
None declared.
}

\section{REFERENCES}

1. Fleurence RL. Setting priorities for research: a practical application of 'payback' and expected value of information. Health Econ. 2007;16:1345-57.

2. Nasser M, Welch V. Prioritization of systematic reviews leads prioritization of research gaps and needs. J Clin Epidemiol. 2013;66:522-3.

3. Shiffman J. Knowledge, moral claims and the exercise of power in global health. Int $\mathrm{J}$ Health Policy Manag. 2014:3:297-9.

4. Murray CJ, Ezzati M, Flaxman AD, Lim S, Lozano R, Michaud C, et al. GBD 2010: design, definitions, and metrics. Lancet. 2012;380:2063-6.

5. Lozano R, Naghavi M, Foreman K, Lim S, Shibuya K, Aboyans V, et al. Global and regional mortality from 235 causes of death for 20 age groups in 1990 and 2010: a systematic analysis for the Global Burden of Disease Study 2010. Lancet. 2012;380:2095-128. Erratum in: Lancet. 2013;381:628.

6. Clarke M, Hopewell S, Chalmers I. Clinical trials should begin and end with systematic reviews of relevant evidence: 12 years and waiting. Lancet. 2010;376:20-1.

7. Jadad AR, Cook DJ, Jones A, Klassen TP, Tugwell P, Moher $M$, et al. Methodology and reports of systematic reviews and meta-analyses: a comparison of Cochrane reviews with articles published in paper-based journals. JAMA. 1998;280:278-80.

8. Collier A, Heilig L, Schilling L, Williams H, Dellavalle RP. Cochrane Skin Group systematic reviews are more methodologically rigorous than other systematic reviews in dermatology. Br J Dermatol. 2006;155:1230-5.
9. Emdin CA, Odutayo A, Hsiao AJ, Shakir M, Hopewell S, Rahimi $\mathrm{K}$, et al. Association between randomised trial evidence and global burden of disease: cross sectional study (Epidemiological Study of Randomized Trials—ESORT). BMJ 2015;350 :h117.

10. Yoong SL, Hall A, Williams CM, Skelton E, Oldmeadow C, Wiggers $\mathrm{K}$, et al. Alignment of systematic reviews published in the Cochrane Database of Systematic Reviews and the Database of Abstracts and Reviews of Effectiveness with global burden of disease data: a bibliographic analysis. J Epidemiol Community Health. J Epidemiol Community Health. $2015 \mathrm{Jul} ; 69(7): 708-14$

11. Pederson H, Okland T, Boyers LN, Karimkhani C, Rosenfeld RM, Nasser M, et al. Identifying otolaryngology systematic review research gaps: comparing Global Burden of Disease 2010 results with Cochrane Database of Systematic Review content. JAMA Otolaryngol Head Neck Surg. 2015;141:67-72.

12. Karimkhani C, Trikha R, Aksut B, Jones T, Boyers LN, Schlichte $M$, et al. Identifying gaps for research prioritisation: Global burden of external causes of injury as reflected in the Cochrane Database of Systematic Reviews. Injury. 2016;47:1151-7.

13. The Cochrane Collaboration. Search the Cochrane library. Available from: http://www.thecochranelibrary.com/view/0/ index.html. Accessed January 15, 2015.

14. World Health Organization. Neglected tropical diseases. Available from: http://www.who.int/neglected_diseases/ diseases/en/. Accessed March 5, 2015.

15. Oxman $A D$, Schünemann $H J$, Fretheim $A$. Improving the use of research evidence in guideline development: 2. Priority setting. Health Res Policy Syst. 2006;4:14.

Correspondence address:

Robert P. Dellavalle, MD, PhD Chief, Dermatology Service

Unites States Department of Veteran Affairs Medical Center 1055 Clermont Street, Box 165 Denver, C0 80220, USA Fax: + 1303 393-4686 E-mail: robert.dellavalle@ucdenver.edu 